Jéssica Fagundes da Cruz

Percepção do suporte organizacional: um estudo de sua relação com o desenvolvimento do comprometimento com a mudança organizacional

Dissertação de Mestrado

Dissertação apresentada ao Programa de Pósgraduação em Administração de Empresas da PUCRio como requisito parcial para obtenção do título de Mestre em Administração de Empresas.

Orientador: Prof. Roger James Volkema Co-Orientadora: Prof ${ }^{a}$.Sandra Regina da Rocha Pinto 
Jéssica Fagundes da Cruz

\section{Percepção do suporte organizacional: um estudo de sua relação com o desenvolvimento do comprometimento com a mudança organizacional}

Dissertação apresentada como requisito parcial para obtenção do título de Mestre pelo Programa de PósGraduação em Administração de Empresas da PUC-Rio. Aprovada pela Comissão Examinadora abaixo assinada.

Prof. Roger James Volkema Orientador

Departamento de Administração - PUC-Rio

Profa. Patrícia Amélia Tomei Departamento de Administração - PUC-Rio

Prof ${ }^{a}$.Sandra Regina da Rocha Pinto Departamento de Administração - PUC-Rio

Prof ${ }^{\text {. Denise Fleck }}$ McGill University, Canadá

Profa Mônica Herz Vice-Decana de Pós-Graduação do CCS 
Todos os direitos reservados. É proibida a reprodução total ou parcial do trabalho sem autorização da autora, dos orientadores e da Univarsidade.

\section{Jéssica Fagundes da Cruz}

Graduou-se em Administração de Empresas na Fundação Escola de Comércio Álvares Penteado (FECAP) de São Paulo em 2004.

Ficha Catalográfica

Cruz, Jéssica Fagundes da

Percepção do suporte organizacional : um estudo de sua relação com o desenvolvimento do comportamento com a mudança organizacional / Jéssica Fagundes da Cruz ; orientadores: Roger James Volkema, Sandra Regina da Rocha Pinto. - 2012.

92 f. : il. (color.) ; $30 \mathrm{~cm}$

Dissertação (mestrado)-Pontifícia Universidade Católica do Rio de Janeiro, Departamento de Administração, 2012.

Inclui bibliografia

1. Administração - Teses. 2. Percepção de suporte organizacional. 3. Comprometimento organizacional. 4. Comprometimento com a mudança organizacional. I. Volkema, Roger. II. Pinto, Sandra Regina da Rocha. III. Pontifícia Universidade Católica do Rio de Janeiro. Departamento de Administração. IV. Título. 


\section{Agradecimentos}

Aos meus familiares, cujo incentivo foi essencial para que mais este projeto de minha vida fosse possível. Aos meus verdadeiros amigos que compreenderam minha ausência durante este período de dedicação e que torceram pelo meu sucesso. 


\section{Resumo}

Cruz, Jéssica Fagundes; Volkema, Roger James. Percepção do suporte organizacional: um estudo de sua relação com o desenvolvimento do comprometimento com a mudança organizacional. Rio de Janeiro, 2012. 92p. Dissertação de Mestrado - Departamento de Administração, Pontifícia Universidade Católica do Rio de Janeiro.

A percepção do suporte organizacional foi associada ao desenvolvimento do comprometimento organizacional e, de acordo com o modelo genérico do comprometimento, pode ser considerado um antecedente do comprometimento direcionado a diferentes alvos como a mudança organizacional. $\mathrm{O}$ comprometimento com as mudanças organizacionais é composto por três componentes - afetivo, instrumental e normativo - que se desenvolvem por diferentes naturezas. Em razão da importância do comprometimento dos funcionários no sucesso das mudanças, o presente estudo tem como objetivo analisar se a percepção do suporte organizacional em sua forma unifatorial e multifatorial tem relação com os componentes do comprometimento com as mudanças organizacionais. Os dados coletados em uma amostra de 126 trabalhadores de uma empresa de energia de grande porte e alunos do curso de mestrado da PUC, ambos do Rio de Janeiro, revelaram que há relação entre os três componentes do comprometimento com as mudanças organizacionais e a percepção do suporte organizacional em sua forma unifatorial, mas a relação não é significante para todos os componentes quando a percepção do suporte organizacional é dividida em mais de um fator (políticas de ascensão, promoção e salário, gestão de desempenho, carga de trabalho e suporte material). São discutidas ainda as limitações da pesquisa e suas implicações e sugestões para futuros estudos.

\section{Palavras-chave}

Mudança Organizacional; Percepção de Suporte Organizacional; Comprometimento Organizacional; Comprometimento com a mudança Organizacional. 


\section{Abstract}

Cruz, Jéssica Fagundes; Volkema, Roger James (Advisor). Perception of organizational support: a study of its relation with the development of the commitment with the organizational change. Rio de Janeiro, 2012. 92p. MSc. Dissertation - Departamento de Administração, Pontifícia Universidade Católica do Rio de Janeiro.

Perceived organizational support was associated with the development of organizational commitment and, according to the generic model of commitment, can be considered an antecedent of commitment when it is directed to different targets such as organizational change. The commitment to organizational change consists of three components - affective, instrumental and normative - that develop by different natures. Because of the importance of employee commitment to the success of the changes, this study aims to analyze the relation of the perception of organizational support in its unifactorial and multifactor forms with the components of commitment to the organizational change. The data collected in a sample of 126 workers of a company of large energy and students of the Masters Course PUC, both of Rio de Janeiro, revealed that there is relationship between the three components of commitment to organizational change and the perception of organizational support unifatorial form, but the relationship is not significant for all components when the perception of organizational support is divided into more than one factor (ascension, promotion and payment, polices, performance management, workload and material support). It is discussed the limitations of the research and its implications and suggestions for future studies.

\section{Keywords}

Organizational Change; Perception Organizational Support; Organizational Commitment; Commitment with Organizational Change. 


\section{Sumário}

1 Descrição do Problema 12

1.1. Introdução 12

1.2. Objetivo da Pesquisa 15

1.3. Relevância do Estudo 17

1.4. Delimitação 18

$\begin{array}{ll}\text { 1.5. Estrutura da Dissertação } & 19\end{array}$

2 Referencial Teórico $\quad 20$

2.1. Comprometimento Organizacional 20

2.1.1. O Comprometimento Organizacional 20

2.1.2. Os antecedentes do Comprometimento Organizacional 29

2.1.3. O Modelo Genérico do Comprometimento 33

2.2. Comprometimento com a Mudança Organizacional 39

2.2.1. Antecedentes do Comprometimento com a Mudança 44

2.2.2. Implicações do Comprometimento com a Mudança 45

2.3. Suporte Organizacional 47

2.4. Hipóteses de Pesquisa 53

3 Método 58

3.1. Amostra 58

3.2. Medida das variáveis 60

3.2.1. Percepção de Suporte Organizacional 60

3.2.2. Comprometimento com a Mudança Organizacional 62

4 Análise dos dados 63

4.1. Análise da confiabilidade das escalas 63

4.1. Correlações e regressões 66

5 Resultados 73

5.1. Discussão 73

5.2. Implicações do estudo 76 
5.3. Limitações do estudo

6 Conclusão 82

7 Referências Bibliográficas $\quad 84$

8 Anexos $\quad 87$ 


\section{Lista de figuras}

Figura 1 - Representação da primeira questão proposta 16

Figura 2 - Representação da segunda questão proposta 17

Figura 3 - Probabilidade do comportamento focal e discricionário 36

Figura 4 - Modelo genérico do comprometimento 38 


\section{Lista de quadros}

Quadro 1 - Componentes do comprometimento organizacional $\quad 29$

Quadro 2 - Antecedentes do comprometimento organizacional 31

Quadro 3 - Subescalas de percepção de suporte organizacional 51

Quadro 4 - Perfil demográfico da amostra 59

Quadro 5 - Percepção de suporte organizacional unifatorial 65

Quadro 6 - Percepção de suporte organizacional multifatorial 65

Quadro 7 - Comprometimento com a mudança 66 


\section{Lista de tabelas}

Tabela 1 - Estatística descritiva e matriz de correlação para percepção de suporte organizacional x comprometimento com a mudança

Tabela 2 - Regressão hierárquica percepção de suporte organizacional unifatorial x comprometimento com a mudança

Tabela 3 - Regressão hierárquica percepção de suporte organizacional multifatorial x comprometimento com a mudança 